IZA DP No. 8054

Land Reforms, Status and Population Growth

Ulla Lehmijoki

Tapio Palokangas

March 2014

Forschungsinstitut zur Zukunft der Arbeit Institute for the Study of Labor 


\title{
Land Reforms, Status and Population Growth
}

\author{
Ulla Lehmijoki \\ University of Helsinki \\ and IZA \\ Tapio Palokangas \\ University of Helsinki \\ and IZA
}

\section{Discussion Paper No. 8054 \\ March 2014}

\author{
IZA \\ P.O. Box 7240 \\ 53072 Bonn \\ Germany \\ Phone: +49-228-3894-0 \\ Fax: +49-228-3894-180 \\ E-mail: iza@iza.org
}

Any opinions expressed here are those of the author(s) and not those of IZA. Research published in this series may include views on policy, but the institute itself takes no institutional policy positions. The IZA research network is committed to the IZA Guiding Principles of Research Integrity.

The Institute for the Study of Labor (IZA) in Bonn is a local and virtual international research center and a place of communication between science, politics and business. IZA is an independent nonprofit organization supported by Deutsche Post Foundation. The center is associated with the University of Bonn and offers a stimulating research environment through its international network, workshops and conferences, data service, project support, research visits and doctoral program. IZA engages in (i) original and internationally competitive research in all fields of labor economics, (ii) development of policy concepts, and (iii) dissemination of research results and concepts to the interested public.

IZA Discussion Papers often represent preliminary work and are circulated to encourage discussion. Citation of such a paper should account for its provisional character. A revised version may be available directly from the author. 
IZA Discussion Paper No. 8054

March 2014

\section{ABSTRACT}

\section{Land Reforms, Status and Population Growth}

In this document, we consider the effects of a land reform on economic and demographic growth by a family-optimization model with sharecropping, endogenous fertility and status seeking. We show that tenant farming is the major obstacle to escaping the Malthusian trap with high fertility and low productivity. A land reform provides peasant families higher returns for their investments in land, encouraging them to increase their productivity of land rather than their family size. This decreases fertility and increases productivity in agriculture in the short and long runs. The European demographic history provides supporting evidence for this.

JEL Classification: $\quad 041, \mathrm{~J} 13, \mathrm{~N} 33$

Keywords: land reforms, population growth, status seeking, sharecropping

Corresponding author:

Ulla Lehmijoki

Department of Economics

P.O. Box 17, Arkadiank. 7

00014 University of Helsinki

Finland

E-mail: ulla.lehmijoki@helsinki.fi 


\section{Introduction}

The core of the Malthusian thinking is the inescapable relationship between population and land: because land is fixed but population growing, a contradiction can not be avoided (Mathus, 1798). This document shows that it is essential to know who owns the land. Land ownership creates incentives to increase the productivity of land and to limit the family size. Therefore, land reforms have often diminished population growth, in particular where land ownership generates social status and appreciation.

Lucas (2002) characterizes land-population relationship by models of human history as follows. In primitive economies, the land is commonly owned so that even altruistic parents cannot improve the lot of their descendants. Once land property rights are established, parents decide on their optimal number of children to whom they hand their farm over. With private ownership, a newcomer decreases income per capita, slowing down population growth in the long run. If parents educate their children, then the costs per newcomer increase, hampering the long-run population growth even further. The transition from high to low fertility occurs only if there is a mechanism through which the agricultural technology is gradually replaced by the modern technology (Lucas 2002). According to Galor et al. (2009), unequal land ownership discourages human capital, preventing the decline in population growth. Because the landowners benefit from cheap labor, they execute their political power to retard overall education. This is why land reforms may trigger modernization and demographic change.

The essential difference between Lucas (2002) and Galor et al. (2009) is that the former focuses on the productive role of land while the latter consider the land as a source of social status and political power. In this paper, we assume that status seeking is important for the peasants as well. If the status depends on the productivity of land, a peasant family has a strong incentive to limit its size. We show that land reforms generate modernization that shifts the economy from the high-fertility and low-income to the low-fertility and high-income equilibrium.

Many economists have recognized the importance of "social status among the peers" in economic dynamics. Adam Smith (1776) emphasizes the appreciation of productive assets as the "Spirit of Capitalism". Kurz (1968), Corneo and Jeanne (2001) and Fisher and Hof (2005) explain the dynamics of advanced economies by the status a household derives from its capital holdings relative to the capital holdings of other households in the economy. Lehmijoki and Palokangas (2009, 2010) explain economic and demographic growth in developing countries by the status of capital holdings among peasant families. On the assumption that a peasant family invests in its farm, 
deriving status from its productivity relative to that of other peasant families, Lehmijoki and Palokangas (2013) show that a land reform decreases fertility. They however make two restrictive assumptions: $(i)$ peasant families can hire or rent land in a competitive market; and $(i i)$ there are no compensations paid to landowners for the transfer of the ownership of land. In this document, we assume that $(i)$ there is sharecropping, with no market for renting land, and $(i i)$ a land reform involves compensations to the landowner.

In most agricultural economies, the landowner rents a farm by taking a share of the crop as a return. Since Stiglitz (1974) and Newbery (1977), economists have explained this behavior by optimal risk-sharing contracts. In this document, we assume that landowners impose sharecropping independently, tenant farmers hide some of their crop and landowners monitor this activity. Consequently, sharecropping is constant in equilibrium.

In the advent of a land reform, sharecropping deceases but the peasant family pays compensations to its former landlord. With full compensations, the initial income of the peasant family does not increase, but the family can still improve its well-being by transferring resources from child rearing to investments in land. This decreases fertility in the short and long run. With partial compensations, the income of the peasant family increases. This tends to promote fertility. However, strong enough status seeking outweighs this, decreasing fertility immediately after the land reform.

This document is organized as follows: Section 2 considers the behavior of the peasant family. Section 3 examines the dynamics of the economy. Sections 4 and 5 consider the long-run and short-run effects of land reforms, illustrating the transition from high fertility and low income to low fertility and high income. Section 7 provides supporting evidence from Europe. Section 8 summarizes the results.

\section{The peasant family}

We examine an economy where all goods are aggregated into one good the price of which is normalized at unity. There two agents: the representative peasant family that produces the good from land and labor, derives utility from its consumption, children and status relative to the other peasant families, and invests in agricultural technology to improve the productivity of the land it cultivates; and the representative landowner that consumes all of its income it collects from the peasant family. This section focuses on the behavior of the peasant family. 


\subsection{Fertility, production and saving}

The peasant family has $L(t)$ members at time $t$. Its (net) fertility rate $n$ is

$$
n \doteq \frac{\dot{L}}{L} \doteq \frac{1}{L} \frac{d L}{d t},
$$

where $\left(^{\circ}\right)$ is the time derivative. The family improves the productivity of land, $A$, by its investment $I$ :

$$
\dot{A} \doteq \frac{d A}{d t}=I .
$$

Normalizing the area of land at unity, the input of efficient land equals $A$.

The number of family members employed in child rearing, $q n L$, is in fixed proportion $q$ to total fertility $n L$ at any time. The rest of the family,

$$
N \doteq L-q n L=(1-q n) L,
$$

works in the family farm. The composite product $Y$ is made from labor input $N$ and efficient land $A$ according to neoclassical technology

$$
\begin{aligned}
& Y=F(N, A), \quad F_{N} \doteq \frac{\partial F}{\partial N}>0, \quad F_{A} \doteq \frac{\partial F}{\partial A}>0, \quad F_{N N} \doteq \frac{\partial^{2} F}{\partial N^{2}}<0 \\
& F_{A A} \doteq \frac{\partial F}{\partial A^{2}}<0, \quad F_{N A} \doteq \frac{\partial^{2} F}{\partial N \partial A}>0, \quad F \text { linearly homogeneous }
\end{aligned}
$$

The landowner rents a farm out to the peasant family taking a share of the crop as a return. The peasant family hides some of its crop with costs and the landowner attempts to monitor this with costs. The interaction of these two agents implies that the peasant family earns (net of hiding costs) the following proportion of its crop $Y$ (cf. Appendix A):

$$
\gamma= \begin{cases}1 & \text { as an independent farmer, } \\ \varpi \in(0,1) & \text { as a tenant farmer. }\end{cases}
$$

Given (5), a land reform can be characterized by $(i)$ an increase of the peasant family's crop share $\gamma$ from $\varpi$ to one and the associated compensations to the former landowner. Because the peasant family is liquidity constrained and has no access to the capital market, its compensations are distributed over a very long time. Thus, it pays a given sum $\tau$ to the landowner at each moment of time over a long period. For mathematical reasons, we assume that the length of that period is infinite.

For the family, investment $I$ is equal to income $\gamma Y$ minus consumption $C$ minus compensations to the landowner, $\tau$. Before the land reform, $\tau=0$. 
Denoting consumption per capita by $c \doteq C / L$ and the productivity of land per capita by $a \doteq A / L$, and noting (2), (3) and (4), the budget constraint of the peasant family becomes

$$
\dot{A}=I=\gamma Y-C-\tau=\gamma F(N, A)-C-\tau=[\gamma F(1-q n, a)-c] L-\tau .
$$

Noting (1) and (6), we obtain the per capita budget constraint

$$
\dot{a}=\frac{\dot{A}}{L}-\frac{\dot{L}}{L} \frac{A}{L}=\frac{\dot{A}}{L}-n a=\gamma F(1-q n, a)-c-n a-\frac{\tau}{L} .
$$

\section{$2.2 \quad$ Utility}

Following Razin and Ben-Zion (1975) and Becker (1991), the family derives temporary utility from the (logarithm of) per capita consumption and the proportion of new people in population, $n$ (= the fertility rate). Because the peasant family saves only by investing in the productivity of land, the productivity of land per capita, $a \doteq A / L$ is a proper measure of its wealth. Each family has the higher status, the more productive land it has per capita (i.e. the higher $a \doteq A / L)$ relative to productive land per capita in the economy $\underline{a}$. Thus, we augment the temporary utility by an increasing function $v(a-\underline{a})$ of the difference $a-\underline{a} .{ }^{1}$ The temporary utility is therefore given by

$$
u(t)=\log c+\theta \log n(t)+\varepsilon v(a(t)-\underline{a}(t)), \quad \theta>0, \quad v^{\prime}>0, \quad v^{\prime}(0)=1,
$$

where $\theta>0$ and $\varepsilon>0$ are the constant weights for children and status. The bigger $\varepsilon$, the stronger status seeking amongst the peasant families. The bigger $\theta$, the more children the families should like to have.

Let the constant $\rho$ be a family's rate of time preference. Noting (1) and (8), the representative peasant family's expected utility at time $t=0$ is then

$$
\begin{aligned}
& U=\int_{0}^{\infty} u(t) e^{-\rho t} d t=\int_{0}^{\infty}[\log c+\theta \log n+\varepsilon v(a-\underline{a})] e^{-\rho t} d t, \\
& v^{\prime}>0, \quad v^{\prime \prime}<0, \quad v^{\prime}(0)=1, \quad \rho>0, \quad \theta>0 .
\end{aligned}
$$

\subsection{The maximization of utility}

The peasant family maximizes its utility (9) by choosing its fertility $n$ and consumption per capita, $c$, subject to its per capita budget constraint (7)

\footnotetext{
${ }^{1}$ This specification is chosen for simplicity. If the measure $v$ were a linearly homogeneous function of $a$ and $\underline{a}$, we would obtain the same results with some complication.
} 
and population growth (1), given the compensations to the landowner, $\tau$. The Hamiltonian of this maximization is

$$
H=\log c+\theta \log n+\epsilon v(a-\underline{a})+\lambda[\gamma F(1-q n, a)-c-n a-\tau / L]+\zeta n L
$$

where the co-state variables $\lambda$ and $\zeta$ evolve according to

$$
\begin{aligned}
& \dot{\lambda}=\rho \lambda-\frac{\partial H}{\partial a}=\left[\rho+n-\gamma F_{A}(1-q n, a)\right] \lambda-\varepsilon v^{\prime}(a-\underline{a}), \quad \lim _{t \rightarrow \infty} \lambda a e^{-\rho t}=0, \\
& \dot{\zeta}=\rho \zeta-\frac{\partial H}{\partial L}=(\rho-n) \zeta-\frac{\tau \lambda}{L^{2}}, \quad \lim _{t \rightarrow \infty} \zeta L e^{-\rho t}=0 .
\end{aligned}
$$

The maximization of the Hamiltonian (10) by the control variables $(c, n)$ for a given $\lambda$ yields the first-order conditions

$$
\frac{\partial H}{\partial c}=\frac{1}{c}-\lambda=0, \quad \frac{\partial H}{\partial n}=\frac{\theta}{n}-\left[\gamma q F_{N}(1-q n, a)+a\right] \lambda=0 .
$$

Given these two equations and (9), we can replace $\lambda$ by $n$ as the co-state variable and define per capita consumption $c$ as a function of efficient land per family member, $a$, and the fertility rate $n$ as follows:

$$
\begin{aligned}
& c \doteq 1 / \lambda=z(a, n, \gamma) / \theta>0, \quad z(a, n, \gamma) \doteq\left[\gamma q F_{N}(1-q n, a)+a\right] n>0 \\
& z_{a} \doteq \frac{\partial z}{\partial a}=(\gamma q \underbrace{F_{N A}}_{+}+1) n>n>0, \quad z_{n} \doteq \frac{\partial z}{\partial n}=\underbrace{\gamma q F_{N}}_{+}+a-\gamma q^{2} n \underbrace{F_{N N}}_{-}>0 \\
& z_{\gamma} \doteq \frac{\partial z}{\partial \gamma}=q n F_{N}(1-q n, a)>0, \quad z=z_{\gamma} \gamma+a n>z_{\gamma} \gamma
\end{aligned}
$$

In the analysis of this document, status seeking plays a crucial role. For that reason, we assume that status seeking [as characterized by the parameter $\varepsilon$ in (8)] is strong enough relative to the desire for having children [as characterized by the parameter $\theta$ in (8)] to satisfy

$$
\frac{\varepsilon}{\theta}>\left\{\frac{z_{a}}{z}\left[\frac{F}{z_{\gamma}}-\frac{1}{\theta}-\frac{F_{A}}{z_{\gamma}}\right], \frac{1}{2}\left[\frac{1}{z}\left(\rho-\frac{z_{a}}{\theta}\right)-\gamma \frac{F_{A A}}{z_{a}}\right], \frac{1}{n} \frac{z_{a}}{z_{n}},-\gamma \frac{F_{A A}}{z_{a}}\right\} .
$$

These critical values for $\frac{\varepsilon}{\theta}$ dictate the dynamics of the economy. Appendices $\mathrm{C}$ and $\mathrm{D}$ provide the details. 


\section{The dynamics of the economy}

The dynamics of the system (7) and (11) can be analyzed without the equation (12) (cf. Appendix B). From (7) and (14) it follows that

$$
\left.F(1-q n, a)\right|_{\dot{a}=0}=(c+a n+\tau / L) / \gamma>c / \gamma=z /(\theta \gamma)>z_{\gamma} / \theta .
$$

Given (14) and (16), the per capita investment (7) has the properties:

$$
\begin{aligned}
& \frac{\partial \dot{a}}{\partial n}=-\gamma q F_{N}(1-q n, a)-a-\frac{\partial c}{\partial n}=-\frac{z}{n}-\frac{z_{n}}{\theta}<0, \\
& \frac{\partial \dot{a}}{\partial a}=\gamma F_{A}(1-q n, a)-n-\frac{\partial c}{\partial a}=\gamma F_{A}(1-q n, a)-n-\frac{z_{a}}{\theta}, \\
& \frac{\partial \dot{a}}{\partial \gamma}=F(1-q n, a)-\frac{\partial c}{\partial \gamma}=F(1-q n, a)-\frac{z_{\gamma}}{\theta}>0, \quad \frac{\partial \dot{a}}{\partial \tau}=-\frac{1}{L}<0 .
\end{aligned}
$$

Because all peasant families and all landowners are identical, efficient land per family member is uniform in the economy, $\underline{a}=a$, in equilibrium. Given $\underline{a}=a,(9)$ and (14), we can transform the differential equation (11) into

$$
\begin{aligned}
& \rho+n-\gamma F_{A}(1-q n, a)-\frac{\varepsilon}{\theta} z(a, n, \gamma)=\rho+n-\gamma F_{A}(1-q n, a)-\frac{\varepsilon}{\lambda} \\
& =\rho+n-\gamma F_{A}(1-q n, a)-v^{\prime}(0) \frac{\varepsilon}{\lambda}=\frac{\dot{\lambda}}{\lambda}=\frac{d \log \lambda}{d t}=-\frac{d}{d t} \log z(a, n) \\
& =-\frac{z_{a}}{z} \dot{a}-\frac{z_{n}}{z} \dot{n} .
\end{aligned}
$$

Rearranging terms in (20), and noting (14) and (17)-(19), we obtain

$$
\dot{n}=\frac{z}{z_{n}}\left[\gamma F_{A}(1-q n, a)+\frac{\varepsilon}{\theta} z(a, n, \gamma)-n-\rho\right]-\frac{z_{a}}{z_{n}} \dot{a}
$$

with the following partial derivatives (cf. Appendix C):

$$
\begin{aligned}
& \left.\frac{\partial \dot{n}}{\partial a}\right|_{\dot{a}=\dot{n}=0}=\frac{z}{z_{n}}\left(\gamma F_{A A}+\frac{\varepsilon}{\theta} z_{a}\right)-\frac{z_{a}}{z_{n}} \frac{\partial \dot{a}}{\partial a}>0,\left.\quad \frac{\partial \dot{n}}{\partial n}\right|_{\dot{a}=\dot{n}=0}=z \frac{\varepsilon}{\theta}+\frac{z_{a}}{\theta}>0, \\
& \left.\frac{\partial \dot{n}}{\partial \gamma}\right|_{\dot{a}=\dot{n}=0}=\frac{z}{z_{n}}\left(F_{A}+\frac{\varepsilon}{\theta} z_{\gamma}\right)-\frac{z_{a}}{z_{n}} \frac{\partial \dot{a}}{\partial \gamma}>0, \quad \frac{\partial \dot{n}}{\partial \tau}=-\frac{z_{a}}{z_{n}} \frac{\partial \dot{a}}{\partial \tau}=\frac{z_{a}}{z_{n}} \frac{1}{L}>0 \\
& \frac{\partial \dot{n}}{\partial \gamma}+\left.\frac{\partial \dot{n}}{\partial \tau} \frac{d \tau}{d \gamma}\right|_{\dot{a}=0}=\underbrace{\frac{z}{z_{n}}}_{+}(\underbrace{F_{A}+\frac{\varepsilon}{\theta} z_{\gamma}}_{+})-\frac{z_{a}}{z_{n}}\left(\frac{\partial \dot{a}}{\partial \gamma}+\left.\frac{\partial \dot{a}}{\partial \tau} \frac{d \tau}{d \gamma}\right|_{\dot{a}=0}\right) .
\end{aligned}
$$

The system (7) and (21) of per capita efficient land, $a$, and fertility $n$ can be linearized in the neighborhood of the steady state $\dot{a}=\dot{n}=0$ :

$$
\left(\begin{array}{cc}
\partial \dot{a} / \partial a & \partial \dot{a} / \partial n \\
\partial \dot{n} / \partial a & \partial \dot{n} / \partial n
\end{array}\right)\left(\begin{array}{c}
d a \\
d n
\end{array}\right)+\left(\begin{array}{cc}
\partial \dot{a} / \partial \gamma & \partial \dot{a} / \partial \tau \\
\partial \dot{n} / \partial \gamma & \partial \dot{n} / \partial \tau
\end{array}\right)\left(\begin{array}{c}
d \gamma \\
d \tau
\end{array}\right)=0
$$


If the Jacobian of this system is negative,

$$
\mathcal{J} \doteq \frac{\partial \dot{a}}{\partial a} \frac{\partial \dot{n}}{\partial n}-\frac{\partial \dot{a}}{\partial n} \frac{\partial \dot{n}}{\partial a}<0
$$

then the system has a saddle point: there is only one initial value of the jump variable $n$ that leads to the steady state. We assume this to be the case. Noting (17) and (22), the condition (25) indicates that

$$
\frac{\partial \dot{a}}{\partial a} \underbrace{\frac{\partial \dot{n}}{\partial n}}_{+}<\frac{\partial \dot{a}}{\partial n} \frac{\partial \dot{n}}{\partial a} \text { and } \frac{\partial \dot{a}}{\partial a}<\underbrace{\frac{\partial \dot{a}}{\partial n}}_{-} \underbrace{\frac{\partial \dot{n}}{\partial a}}_{+} / \underbrace{\frac{\partial \dot{n}}{\partial n}}_{+}<0 .
$$

\section{Long-run effects of a land reform}

In a land reform, the peasant family's share $\gamma$ increases from $\varpi \in(0,1)$ to 1. We consider first the effect of $\gamma$ on the assumption that $\gamma$ is a continuous variable in the limit $[\varpi, 1]$. Later on, we generalize the results for the discrete choice $\gamma \in\{\varpi, 1\}$.

We call a land reform fully-compensated, if the peasant family pays such compensations $d \tau>0$ to its former landowner that its wealth $a$ is kept constant [cf. (7)]:

$$
\frac{\partial \dot{a}}{\partial \gamma}+\left.\frac{\partial \dot{a}}{\partial \tau} \frac{d \tau}{d \gamma}\right|_{\dot{a}=0}=0 \text { for a fully-compensated reform. }
$$

Noting (4), (14), (15), (17), (22), (23), (25) and (26), the steady state values $a^{*}$ and $n^{*}$ are functions of preferences concerning status relative to children, $\varepsilon / \theta$, and the peasant family share of output, $\gamma$, and the family's compensations $\tau$ with the following properties (cf. Appendix D):

$$
\begin{aligned}
& \frac{\partial a^{*}}{\partial \gamma}+\left.\frac{\partial a^{*}}{\partial \tau} \frac{\partial \tau}{\partial \gamma}\right|_{\dot{a}=0}>0, \quad \frac{\partial n^{*}}{\partial \gamma}+\left.\frac{\partial n^{*}}{\partial \tau} \frac{\partial \tau}{\partial \gamma}\right|_{\dot{a}=0}<0 \\
& \frac{\partial a^{*}}{\partial \tau}=\frac{1}{\mathcal{J}} \frac{z}{L}\left(\frac{\varepsilon}{\theta}-\frac{z_{a}}{n z_{n}}\right)<0, \quad \frac{\partial n^{*}}{\partial \tau}=-\frac{1}{L} \frac{z}{\mathcal{J}} \frac{z_{a}}{z_{n}}\left(\gamma \frac{F_{A A}}{z_{a}}+\frac{\varepsilon}{\theta}\right)>0 .
\end{aligned}
$$

The two first inequalities in (28) can be rephrased as follows: ${ }^{2}$

Proposition 1 A fully-compensated land reform increases per capita efficient land $a^{*}$, but decreases the fertility rate $n^{*}$ in the long run.

A fully-compensated land reform increases the peasant family's crop share $\gamma$ and the rate of return for investment in land. Consequently, the peasant family transfers its resources from child rearing to investment in land.

\footnotetext{
${ }^{2}$ Because proposition 1 holds for all values $\gamma \in[\varpi, 1]$, it holds also for the discrete change in which a tenant farmer with $\gamma=\varpi<1$ becomes an independent farmer $\gamma=1$.
} 


\section{Short-run effects of a land reform}

Consider the short-run evolution of the economy. Given (19), (22) and (25), both singular curves $(\dot{a}=0)$ and $(\dot{n}=0)$ are decreasing, but $(\dot{a}=0)$ falls more steeply: in the $(a, n)$ space:

$$
\left.\frac{\partial n}{\partial a}\right|_{\dot{a}=0}=-\frac{\partial \dot{a}}{\partial a} / \underbrace{\frac{\partial \dot{a}}{\partial n}}_{-}<-\underbrace{\frac{\partial \dot{n}}{\partial a}}_{+} / \underbrace{\frac{\partial \dot{n}}{\partial n}}_{+}=\left.\frac{\partial n}{\partial a}\right|_{\dot{r}=0}<0 .
$$

Since $\partial \dot{a} / \partial n<0$ by (17), efficient land per family member, $a$, increases (decreases) below (above) the singular curve $(\dot{a}=0)$. Since $\partial \dot{n} / \partial n>0$ by (22), the fertlity rate $n$ increases (decreases) above (below) the singular curve $(\dot{n}=0)$. Hence, the stable saddle path $S S$ is downward sloping (cf. Fig. 1).

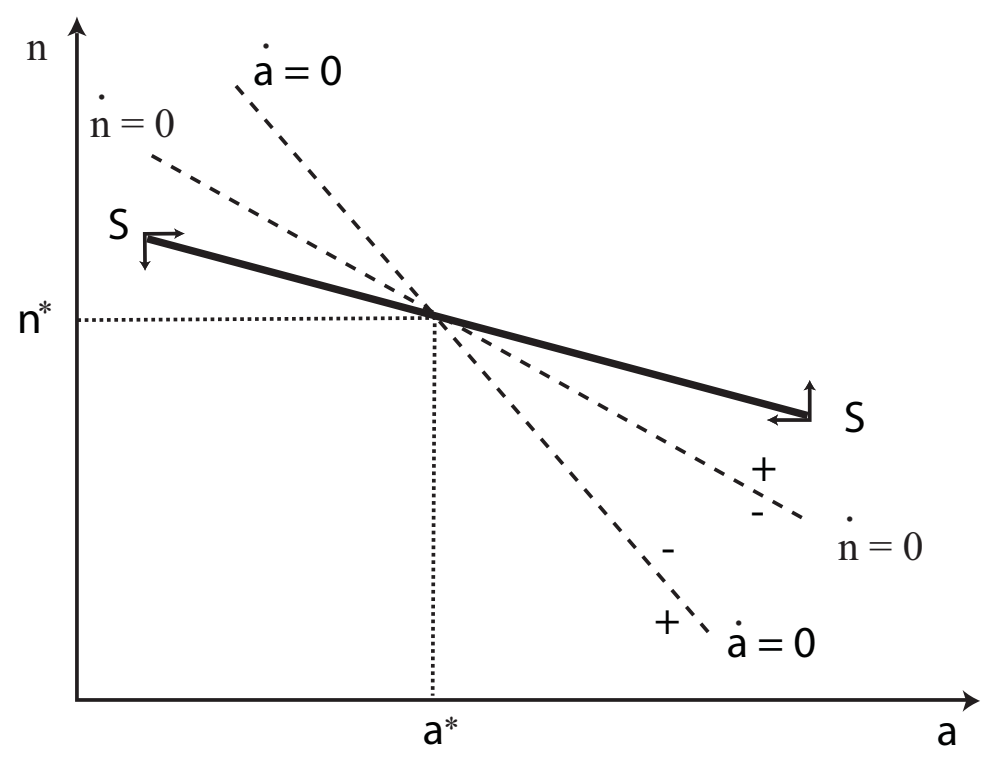

Figure 1: The phase diagram: the dynamics of the model.

Noting (19), (22), (23) and (26), we obtain

$$
\begin{aligned}
& \left.\frac{d n}{d \gamma}\right|_{\dot{n}=0}=-\underbrace{\frac{\partial \dot{n}}{\partial \gamma}}_{+} / \underbrace{\frac{\partial \dot{n}}{\partial n}}_{+}<0,\left.\quad \frac{d n}{d \gamma}\right|_{\dot{a}=0}=-\underbrace{\frac{\partial \dot{a}}{\partial \gamma}}_{+} / \underbrace{\frac{\partial \dot{a}}{\partial a}}_{-}>0, \\
& \left.\frac{d n}{d \tau}\right|_{\dot{n}=0}=-\underbrace{\frac{\partial \dot{n}}{\partial \tau}}_{+} / \underbrace{\frac{\partial \dot{n}}{\partial n}}_{+}<0,\left.\quad \frac{d n}{d \tau}\right|_{\dot{+}=0}=-\underbrace{\frac{\partial \dot{a}}{\partial \tau}}_{-} / \underbrace{\frac{\partial \dot{a}}{\partial a}}_{-}<0 .
\end{aligned}
$$


Given these inequalities, (22), (23) and (27), we obtain that a fully-compensated land reform shifts curve $(\dot{n}=0)$ downwards, but does not affect curve $(\dot{a}=0)$ :

$$
\begin{aligned}
& \left(\frac{d n}{d \gamma}+\left.\frac{d n}{d \tau} \frac{d \tau}{d \gamma}\right|_{\dot{a}=0}\right)_{\dot{n}=0}=-(\underbrace{\frac{\partial \dot{n}}{\partial \gamma}+\left.\frac{\partial \dot{n}}{d \tau} \frac{d \tau}{d \gamma}\right|_{\dot{a}=0}}_{+}) / \underbrace{\frac{\partial \dot{n}}{\partial n}}_{+}<0, \\
& \left(\frac{d a}{d \gamma}+\left.\frac{d a}{d \tau} \frac{d \tau}{d \gamma}\right|_{\dot{a}=0}\right)_{\dot{a}=0}=-(\underbrace{\frac{\partial \dot{a}}{\partial \gamma}+\left.\frac{\partial \dot{a}}{d \tau} \frac{d \tau}{d \gamma}\right|_{\dot{a}=0}}_{=0}) / \underbrace{\frac{\partial \dot{a}}{\partial n}}_{+}=0 .
\end{aligned}
$$

Assume first that the system is initially in the steady state $\left(a_{0}^{*}, n_{0}^{*}\right)$. Once $\gamma$ increases, the steady state moves to $\left(a_{1}^{*}, n_{1}^{*}\right)$. Given proposition 1 , the efficient land per family member, $a$, rises but the fertility rate $n$ falls, $a_{0}^{*}<a_{1}^{*}$ and $n_{0}^{*}>n_{1}^{*}$. The fertility rate $n$ falls immediately $n_{0}^{*} \rightarrow \widehat{n}_{1}$. After that, the economy moves along the saddle path $S_{1} S_{1}$ to the new steady state $\left(a_{1}^{*}, n_{1}^{*}\right){ }^{3}$ The resulting dynamics can be rephrased as follows (cf. Fig. 2).

Proposition 2 The fully-compensated land reform decreases the fertility rate $n$ immediately $\left(n_{0}^{*} \rightarrow \widehat{n}_{1}\right)$.

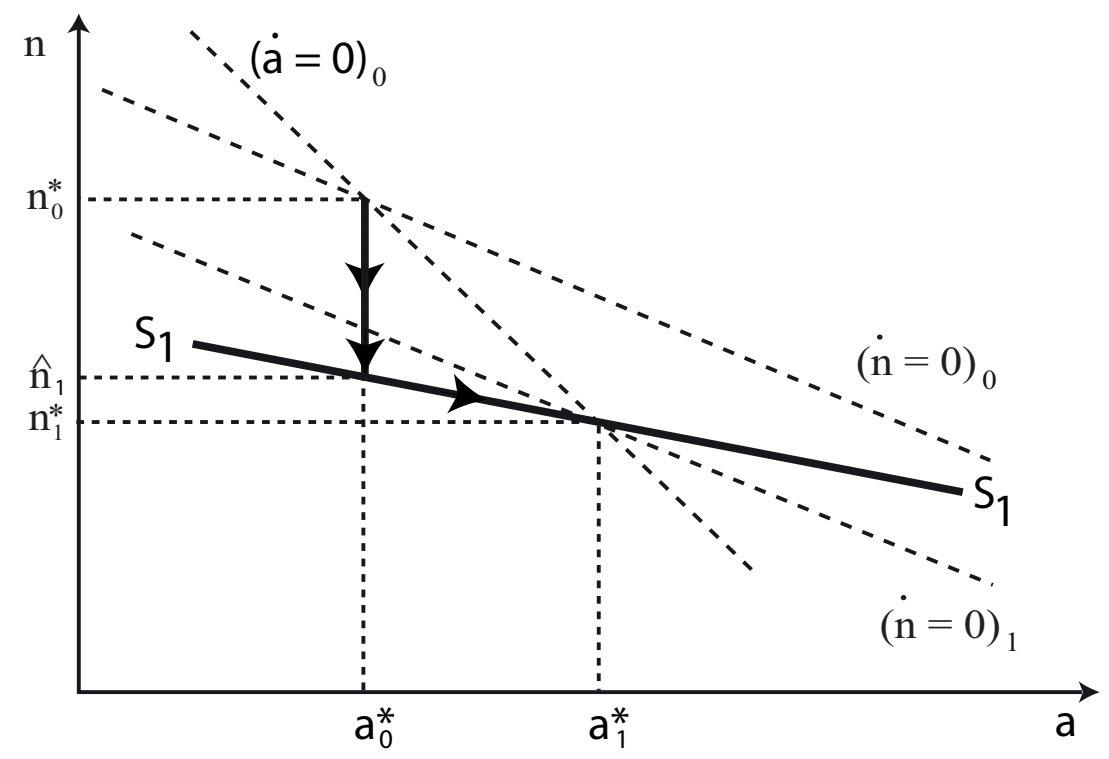

Figure 2: The development of per capita productivity $a$ and population growth $n$ after a fully-compensated land reform.

\footnotetext{
${ }^{3}$ Because proposition 2 holds for all values $\gamma \in[\varpi, 1]$, it holds also for the discrete change in which a tenant farmer with $\gamma=\varpi<1$ becomes an independent farmer $\gamma=1$.
} 
With a fully-compensated land reform, the substitution effect determines the patterns of development: the family raises its status by transferring resources from child rearing to investment in efficient land $a$ and fertility decreases.

\section{Partial compensations}

The two preceding sections focused on the substitution effect of a land reform on the assumption that the reform is fully-compensated. In that case, a land reform leads to the equilibrium $\left(a_{1}^{*}, n_{1}^{*}\right)$ (cf. Fig. 2). To examine the effect of partial compensations, we take the fully-compensated equilibrium $\left(a_{1}^{*}, n_{1}^{*}\right)$ as a starting point and assume that the compensations to the landowner, $\tau$, are decreased. Given (28), this increases long-term effcient land per family member, $a_{1}^{*} \rightarrow a_{2}^{*}$, (cf. $\frac{\partial a^{*}}{\partial \tau}<0$ ), and decreases the long-term effcient fertility rate, $n_{1}^{*} \rightarrow n_{2}^{*}\left(\right.$ cf. $\left.\frac{\partial n^{*}}{\partial \tau}>0\right)$ ). Given (30), both $(\dot{n}=0)$ and $(\dot{a}=0)$ move upwards (cf. $\left.\frac{d n}{d \tau}\right|_{\dot{n}=0}<0$ and $\left.\frac{d n}{d \tau}\right|_{\dot{a}=0}<0$ ). The resulting dynamics is in Fig. 3.

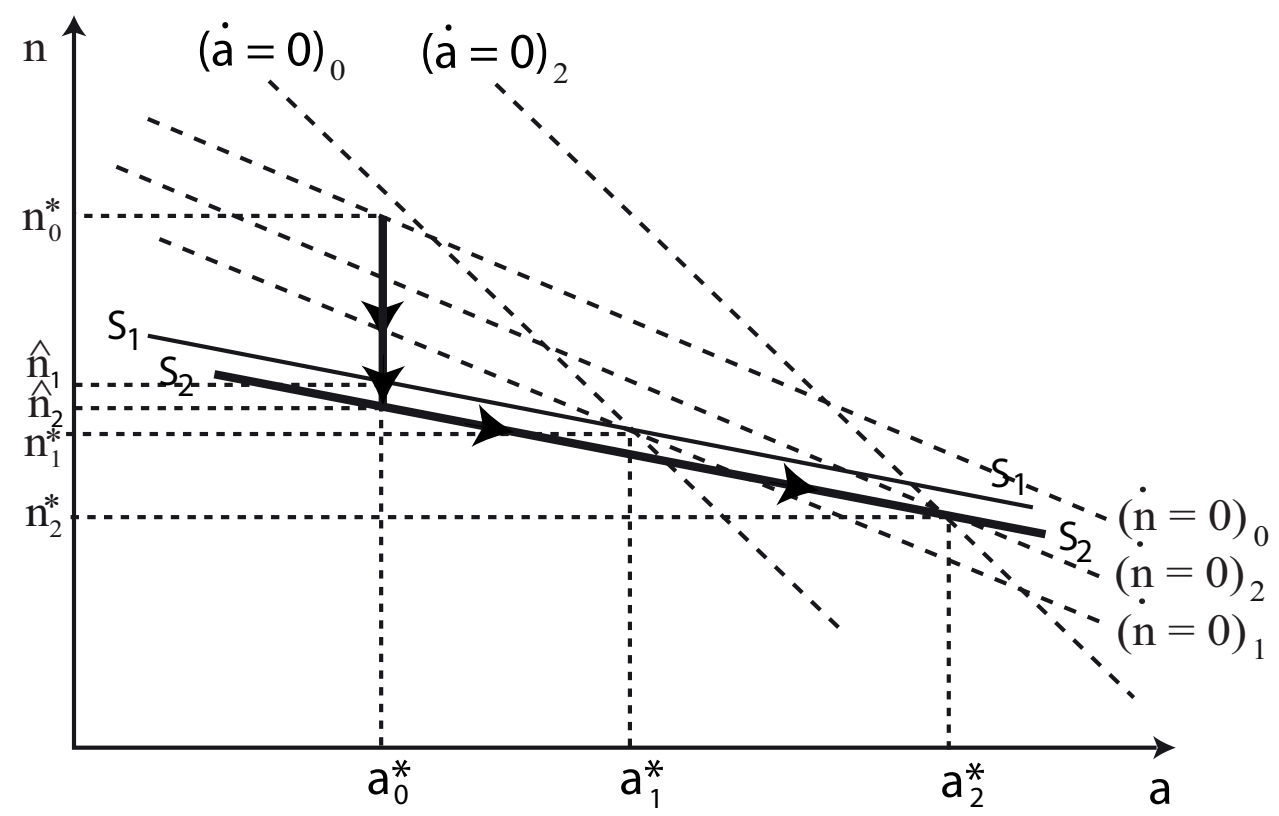

Figure 3: The effects of partial compensations.

We conclude:

Proposition 3 In the long run, the income effect due to partial compensations (i.e. a decrease of $\tau$ ) amplifies the increase in the productivity of land $\left(a_{2}^{*}-a_{0}^{*}>a_{1}^{*}-a_{0}^{1}\right)$ and the decrease in the fertility rate $\left(n_{0}^{*}-n_{2}^{*}>n_{0}^{*}-n_{0}^{1}\right)$. 
Higher initial income due to partial compensations increases fertility because children are normal goods. On the other hand, the peasant family saves and invests in the productivity of land so that the marginal productivity of labor in production increases, attracting labor from child rearing to production (the substitution effect). With strong status seeking [c.f. (15)], the latter dominates and fertility falls in the long run, $n_{2}^{*}<n_{1}^{*}$.

Figure 3 illustrates the short-run response of the economy when the saddle path $S_{2} S_{2}$ for the partial-compensation equilibrium $\left(a_{2}^{*}, n_{2}^{*}\right)$ is below that $S_{1} S_{1}$ for the full-compensation equilibrium $\left(a_{1}^{*}, n_{1}^{*}\right)$, and the short-run fall in fertility is greater with partial than that with full compensations, $\widehat{n}_{2}<\widehat{n}_{1}$. In Appendix E, we show that this case holds true if

$$
\begin{aligned}
\gamma F_{A A} & +\frac{z_{a}^{2}}{n z_{n}}>\frac{1}{4}\left(\frac{n+\rho-\gamma F_{A}}{z}-\frac{z_{a}}{n z_{n}}\right)^{2} \text { or } \\
\frac{\varepsilon}{\theta}> & \frac{1}{2}\left(\frac{n+\rho-\gamma F_{A}}{z}+\frac{z_{a}}{n z_{n}}\right) \\
& +\frac{1}{2} \sqrt{\left(\frac{n+\rho-\gamma F_{A}}{z}-\frac{z_{a}}{n z_{n}}\right)^{2}-4\left(\gamma F_{A A}+\frac{z_{a}^{2}}{n z_{n}}\right) \frac{1}{z^{2}} \frac{d a}{d t}} .
\end{aligned}
$$

We conclude:

Proposition 4 With strong enough status seeking [i.e. with (31)], the income effect due to partial compensations (i.e. a decrease in $\tau$ ) makes the immediate fall in fertility more drastic [i.e. $\widehat{n}_{2}<\widehat{n}_{1}$ in Fig. 3].

\section{Supportive evidence}

Next, we provide suggestive evidence on the effects of land reforms in Europe.

One of the greatest puzzles in demographic history is why fertility declined in rich and urbanized England much later than in poor and rural France. ${ }^{4}$ Figure 4 illustrates the fertility trends in England, France, and Germany from 1831-1840 to 1936-1945, showing that even though fertility was declining everywhere, its level in 1831-1840 was much lower and its decrease much faster in France. ${ }^{5}$ If economic factors were the driving forces of the fertility decline, this should have started first in England. Nevertheless, this was not

\footnotetext{
${ }^{4}$ In 1820, the GDP per capita in England was 1.4 times larger than that in France, and the advantage of England only increased towards the end of the century (Maddison 1995, 194-196).

${ }^{5}$ The cohort fertility rate in Figure 4 gives the total number of births given by women born in the time period indicated in the Figure.
} 
Cohort fertility rate (children per woman)

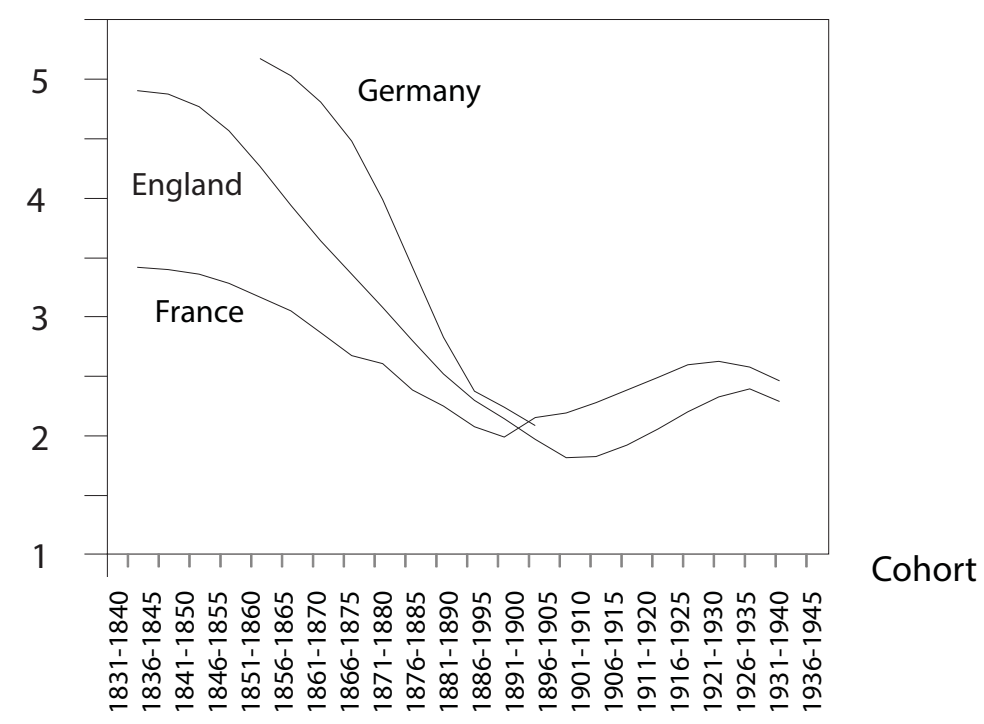

Figure 4: The decline of fertility in France, England and Germany. Source: Festy (1979, pages 266-67, 262 and 222).

the case. In 1831-1840, the fertility in England was over $40 \%$ higher than in France. Furthermore, it took over 30 years for England to reach the 18311840 numbers in France. On the other hand, England was ahead of Germany as one expected (cf. Fig. 4). Why was the fertility rate so low in France?

Figure 5 presents the (marital) fertility in France from 1740 to 1911. It shows that fertility declined sharply at the time of the land reform during the Great Revolution 1789-1799, while no land reform occurred in England or Germany: in $1830,63 \%$ of the population was landowning peasants in France, while in Britain the share of landowners was only 14\% (Chesnais 1992, p. 337). Actually, the widespread ownership of land was a unique feature of France (Gummins 2012). For the new rural bourgeoisie class, fertility control was a powerful method for social advance. Thus, the fertility decline in France was likely due to the decline in the child demand among the peasants (Gummins 2012). Furthermore, by associating early wealth and fertility data, Gummings shows that those peasants who had the greatest land property also had the lowest fertility and their fertility decline was the fastest, indicating that status seeking may have played an important role. 


\section{Marital fertility rate in France}

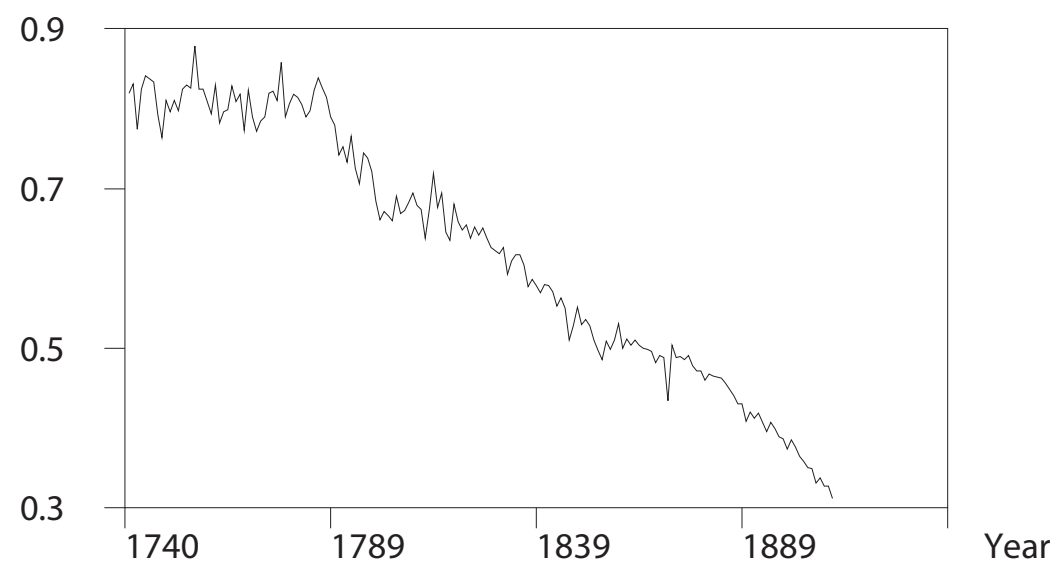

Figure 5: The marital fertility rate expressed as the share of the maximum fertility rate (1.00) in France. Source: Weir 1994.

\section{Conclusions}

This paper examines the effects of land reforms by a family-optimization model with endogenous fertility and status seeking. A land reform generates a higher rate of return to investment for peasant families. The outcome of this depends on preferences. If the role of status is strong enough, then peasants limit their family size and invest in the improvement of land.

Where the land reform is not fully compensated, the peasant families get a transfer of income from the landowners. This increase in income generates investment in the productivity of land. When land becomes more productive, the marginal product of labor in production increases, which encourages the family to transfer labor from child rearing to production. This decreases fertility and increases the productivity of land in the long run even more than in the case of a fully-compensated land reform. Because children are normal goods for the peasant families, the increase in income can raise the demand for children in the short run, partially outweighing the immediate fall in fertility.

The demographic history in Europe provides supportive evidence for this land-reform hypothesis. Fertility declined in rich and urbanized England much later than in poor and rural France due to the land reform in the latter during Great Revolution 1789-1799. The fertility control, which supplied a powerful method for social rise to the new rural bourgeois class, led to an exceptional fertility decline in France. There is evidence that the peasants 
with the greatest land property had the lowest fertility indicating they were subject to strong status seeking.

\section{Appendix}

\section{A Sharecropping}

We assume that the peasant family is able to hide some of its crop $Y$ at some cost $E$, but the landowner can increase these costs $E$ by allocating resources $M$ to monitoring and policing. Let $\xi Y$ be hidden crop and $(1-\xi) Y$ revealed crop, where $\xi \in[0,1]$. We assume that the size of the family does not affect the ability to conceal crop, but that such activity is subject to increasing costs. This means that the cost of hiding crop, $E$, is proportional to total crop $Y$, but increasing with respect to the ratio $\xi \doteq E / Y$ of hidden to total crop and the ratio $m \doteq M / Y$ of motoring costs to total crop $Y$. It is obvious that with all profits revealed, $\xi=0$, there is no cost, $E=0$. Given these assumptions, we obtain the cost function

$$
E=b(\xi, m) Y, \quad \frac{\partial b}{\partial \xi}>0, \quad \frac{\partial b}{\partial m}>0, \quad b(0, m)=0,
$$

where $b$ is the ratio of costs to total crop. We assume that the function $b(\xi, m)$ twice differentiable, for convenience.

The landowner claims the share $\chi \in[0,1]$ of revealed crop $(1-\xi) Y$. Its rents are then equal to

$$
\Upsilon \doteq \chi(1-\xi) Y
$$

The peasant family earns crop $Y$ minus rents (33) and hiding costs (32):

$$
\Pi \doteq Y-\Upsilon-E=[1-(1-\xi) \chi-b(\xi, m)] Y .
$$

The peasant family maximizes its income (34) by its hiding proportion $\xi$, given cropsharing $\chi$ and total crop $Y$. The first-order condition $\partial \Pi / \partial \xi=0$

is equivalent to $\chi=\frac{\partial b}{\partial m}(\xi, m)$. Differentiating this totally, we obtain the response function of the peasant family as follows:

$$
\xi(\chi, m), \quad \frac{\partial \xi}{\partial \chi}=1 / \frac{\partial^{2} b}{\partial \xi^{2}}, \quad \frac{\partial \xi}{\partial m}=-\frac{\partial^{2} b}{\partial \xi \partial m} / \frac{\partial^{2} b}{\partial \xi^{2}} .
$$

The landowner earns rents (33) minus monitoring costs $M=m Y$. Given the response function (35), this target becomes

$$
\Upsilon \doteq \chi(1-\xi) Y-M=[\chi-\xi(\chi, m) \chi-m] Y .
$$


The landowner maximizes (36) by cropsharing $\chi$ and the ratio $m$, given total crop $Y$. This implies that both $\chi$ and $m$ are constants:

$$
(\chi, m)=\arg \max _{\chi, m} \Upsilon=\arg \max _{\chi, m}[\chi-\xi(\chi, m) \chi-m] .
$$

Given (34) and (35), The income of the peasant family (net of hiding costs) relative to total crop is then constant

$$
\varpi \doteq \Pi / Y=1-(1-\xi) \chi-b(\xi, m) \in(0,1)
$$

Because an independent farmer has neither hiding costs $\xi$ nor the landowner's claims $\chi$, it earns total crop [cf. (32) and (34)]

$$
\left.\Pi\right|_{\xi=\chi=0}=[1-b(0, m)] Y=Y .
$$

\section{B The elimination of equation (12)}

Because the proportion of new people in the family is a normal good in the family preferences, the family grows indefinitely [cf. (1), (4) and (14)]:

$$
\dot{L} / L=n=z /\left(\gamma q F_{N}+a\right)=\theta c /\left(\gamma q F_{N}+a\right)>0, \quad \lim _{t \rightarrow \infty} L=\infty .
$$

Consequently, the compensations per family member vanishes, $\lim _{t \rightarrow \infty} \tau / L=$ 0 . Assume that the system (7) and (11) converges to the unique steady state $(a, \lambda, n, c)=\left(a^{*}, \lambda^{*}, n^{*}, c^{*}\right)$ where

$$
\gamma F\left(1-q n^{*}, a^{*}\right)=c^{*}+n^{*} a^{*}, \quad \rho+n-\gamma F_{A}\left(1-q n^{*}, a^{*}\right)=\varepsilon v^{\prime}\left(a^{*}-\underline{a}\right) / \lambda^{*} .
$$

Because in this case, by (1) and (12), one obtains

$$
\begin{aligned}
& \frac{d}{d t} \log \left(\zeta L e^{-\rho t}\right)=\frac{\dot{\zeta}}{\zeta}+\frac{\dot{L}}{L}-\rho=\rho-n-\frac{\tau \lambda}{L^{2} \zeta}+n-\rho=-\frac{\tau \lambda}{L^{2} \zeta} \\
& \lim _{t \rightarrow \infty} \frac{d}{d t} \log \left(\zeta L e^{-\rho t}\right)=-\frac{\tau \lambda^{*}}{L^{2} \zeta}<0, \quad \lim _{t \rightarrow \infty} \lambda a e^{-\rho t}=\lim _{t \rightarrow \infty} \lambda^{*} a^{*} e^{-\rho t}=0,
\end{aligned}
$$

the transversality conditions $\lim _{t \rightarrow \infty} \lambda a e^{-\rho t}$ and $\lim _{t \rightarrow \infty} \zeta L e^{-\rho t}=0$ hold true. Thus, the dynamics of the system (7) and (11) can be analyzed without involving the equation (12). 


\section{Partial derivatives (22) and (23)}

Given (14), (15) and (17)-(21), we obtain

$$
\begin{aligned}
& \left.\frac{\partial \dot{n}}{\partial a}\right|_{\dot{a}=\dot{n}=0}=\frac{z}{z_{n}}\left(\gamma F_{A A}+\frac{\varepsilon}{\theta} z_{a}\right)-\frac{z_{a}}{z_{n}} \frac{\partial \dot{a}}{\partial a} \\
& =\frac{z}{z_{n}}\left(\gamma F_{A A}+\frac{\varepsilon}{\theta} z_{a}\right)-\frac{z_{a}}{z_{n}}\left(\gamma F_{A}-n-\frac{z_{a}}{\theta}\right) \\
& =\frac{z}{z_{n}}\left(\gamma F_{A A}+\frac{\varepsilon}{\theta} z_{a}\right)-\frac{z_{a}}{z_{n}}\left(\rho-\frac{\varepsilon}{\theta} z-\frac{z_{a}}{\theta}\right) \\
& =\frac{z}{z_{n}}\left(\gamma F_{A A}+2 \frac{\varepsilon}{\theta} z_{a}\right)-\frac{z_{a}}{z_{n}}\left(\rho-\frac{z_{a}}{\theta}\right)=\frac{z_{a}}{z_{n}}\left[z\left(\gamma \frac{F_{A A}}{z_{a}}+2 \frac{\varepsilon}{\theta}\right)-\left(\rho-\frac{z_{a}}{\theta}\right)\right] \\
& =\underbrace{2 z \frac{z_{a}}{z_{n}}}_{+}\left\{\frac{\varepsilon}{\theta}+\frac{1}{2}\left[\gamma \frac{F_{A A}}{z_{a}}-\frac{1}{z}\left(\rho-\frac{z_{a}}{\theta}\right)\right]\right\}>0, \\
& \left.\frac{\partial \dot{n}}{\partial n}\right|_{\dot{a}=\dot{n}=0}=\frac{z}{z_{n}}\left(\frac{\varepsilon}{\theta} z_{n}-\gamma F_{N A} q-1\right)-\frac{z_{a}}{z_{n}} \frac{\partial \dot{a}}{\partial n} \\
& =\frac{z}{z_{n}}\left(\frac{\varepsilon}{\theta} z_{n}-\frac{z_{a}}{n}\right)+\frac{z_{a}}{z_{n}}(\underbrace{q \gamma F_{N}+a}_{=z / n}+\frac{z_{n}}{\theta})=\frac{z}{z_{n}} \frac{\varepsilon}{\theta} z_{n}+\frac{z_{a}}{z_{n}} \frac{z_{n}}{\theta}=z \frac{\varepsilon}{\theta}+\frac{z_{a}}{\theta}>0 \\
& \left.\frac{\partial \dot{n}}{\partial \gamma}\right|_{\dot{a}=\dot{n}=0}=\frac{z}{z_{n}}\left(F_{A}+\frac{\varepsilon}{\theta} z_{\gamma}\right)-\frac{z_{a}}{z_{n}} \frac{\partial \dot{a}}{\partial \gamma} \\
& =\frac{z}{z_{n}}\left(F_{A}+\frac{\varepsilon}{\theta} z_{\gamma}\right)-\frac{z_{a}}{z_{n}}\left[F(1-q n, a)-\frac{z_{\gamma}}{\theta}\right] \\
& =z \frac{z_{\gamma}}{z_{n}}\left\{\frac{F_{A}}{z_{\gamma}}+\frac{\varepsilon}{\theta}-\frac{z_{a}}{z}\left[\frac{F(1-q n, a)}{z_{\gamma}}-\frac{1}{\theta}\right]\right\}>0 .
\end{aligned}
$$

\section{Partial derivatives (28)}

Noting (4), (14), (15), (27), (17), (19), (22), (23), (24), (25) and (26), we obtain

$$
\begin{aligned}
& \frac{\partial a^{*}}{\partial \gamma}+\left.\frac{\partial a^{*}}{\partial \tau} \frac{\partial \tau}{\partial \gamma}\right|_{\dot{a}=0}=-\frac{1}{\mathcal{J}}\left|\begin{array}{ll}
\frac{\partial \dot{a}}{\partial \gamma}+\left.\frac{\partial \dot{a}}{\partial \tau} \frac{\partial \tau}{\partial \gamma}\right|_{\dot{a}=0} & \frac{\partial \dot{a}}{\partial n} \\
\frac{\partial n}{\partial \gamma}+\left.\frac{\partial \dot{n}}{\partial \tau} \frac{\partial \tau}{\partial \gamma}\right|_{\dot{a}=0} & \frac{\partial \dot{n}}{\partial n}
\end{array}\right| \\
& =-\frac{1}{\mathcal{J}}\left|\begin{array}{cc}
0 & \frac{\partial \dot{a}}{\partial n} \\
\frac{\partial \dot{n}}{\partial \gamma}+\left.\frac{\partial \dot{n}}{\partial \tau} \frac{\partial \tau}{\partial \gamma}\right|_{\dot{a}=0} & \frac{\partial \dot{n}}{\partial n}
\end{array}\right|=\frac{1}{\mathcal{J}} \frac{\partial \dot{a}}{\partial n}\left(\frac{\partial \dot{n}}{\partial \gamma}+\left.\frac{\partial \dot{n}}{\partial \tau} \frac{\partial \tau}{\partial \gamma}\right|_{\dot{a}=0}\right)>0, \\
& \frac{\partial n^{*}}{\partial \gamma}+\left.\frac{\partial n^{*}}{\partial \tau} \frac{\partial \tau}{\partial \gamma}\right|_{\dot{a}=0}=-\frac{1}{\mathcal{J}}\left|\begin{array}{ll}
\frac{\partial \dot{a}}{\partial a} & \frac{\partial \dot{a}}{\partial \gamma}+\left.\frac{\partial \dot{a}}{\partial \tau} \frac{\partial \tau}{\partial \gamma}\right|_{\dot{a}=0} \\
\frac{\partial \dot{n}}{\partial a} & \frac{\partial \dot{n}}{\partial \gamma}+\left.\frac{\partial \dot{n}}{\partial \tau} \frac{\partial \tau}{\partial \gamma}\right|_{\dot{a}=0}
\end{array}\right|
\end{aligned}
$$




$$
\begin{aligned}
& =-\frac{1}{\mathcal{J}}\left|\begin{array}{cc}
\frac{\partial \dot{a}}{\partial a} & 0 \\
\frac{\partial \dot{n}}{\partial a} & \frac{\partial \dot{n}}{\partial \gamma}+\left.\frac{\partial \dot{n}}{\partial \tau} \frac{\partial \tau}{\partial \gamma}\right|_{\dot{a}=0}
\end{array}\right|=-\frac{1}{\mathcal{J}} \frac{\partial \dot{a}}{\partial a}\left(\frac{\partial \dot{n}}{\partial \gamma}+\left.\frac{\partial \dot{n}}{\partial \tau} \frac{\partial \tau}{\partial \gamma}\right|_{\dot{a}=0}\right)<0, \\
& \frac{\partial a^{*}}{\partial \tau}=-\frac{1}{\mathcal{J}}\left|\begin{array}{cc}
\frac{\partial \dot{a}}{\partial \tau} & \frac{\partial \dot{a}}{\partial n} \\
\frac{\partial \dot{n}}{\partial \tau} & \frac{\partial \dot{n}}{\partial n}
\end{array}\right|=-\frac{1}{\mathcal{J}}\left|\begin{array}{cc}
-\frac{1}{L} & -\frac{z}{n}-\frac{z_{n}}{\theta} \\
\frac{z_{a}}{z_{n}} \frac{1}{L} & z \frac{\varepsilon}{\theta}+\frac{z_{a}}{\theta}
\end{array}\right|=-\frac{1}{\mathcal{J}} \frac{z}{L}\left|\begin{array}{cc}
-1 & -\frac{1}{n} \\
\frac{z_{a}}{z_{n}} & \frac{\varepsilon}{\theta}
\end{array}\right| \\
& =\frac{1}{\mathcal{J}} \frac{z}{L}\left(\frac{\varepsilon}{\theta}-\frac{z_{a}}{n z_{n}}\right)<0, \\
& \frac{\partial n^{*}}{\partial \tau}=-\frac{1}{\mathcal{J}}\left|\begin{array}{cc}
\frac{\partial \dot{a}}{\partial a} & \frac{\partial \dot{a}}{\partial \tau} \\
\frac{\partial \dot{n}}{\partial a} & \frac{\partial \dot{n}}{\partial \tau}
\end{array}\right|=-\frac{1}{\mathcal{J}}\left|\begin{array}{cc}
\frac{\partial \dot{a}}{\partial a} & -\frac{1}{L} \\
\frac{z}{z_{n}}\left(\gamma F_{A A}+\frac{\varepsilon}{\theta} z_{a}\right)-\frac{z_{a}}{z_{n}} \frac{\partial \dot{a}}{\partial a} & \frac{z_{a}}{z_{n}} \frac{1}{L}
\end{array}\right|
\end{aligned}
$$

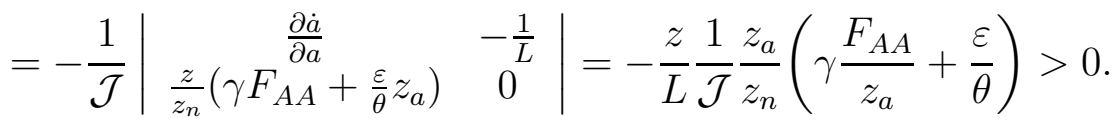

\section{E Inequality (31)}

Because $a$ is increasing on the saddle path $S_{2} S_{2}$ that approaches $\left(a_{2}^{*}, n_{2}^{*}\right)$ from the left, $\frac{d a}{d t}>0$ holds true. Noting this, (14), (15), (21) and (28), we obtain:

$$
\begin{aligned}
& \text { the slope of } S_{2} S_{2}=\frac{d n}{d t} / \frac{d a}{d t}=\underbrace{\frac{z}{z_{n}}}_{+}\left(\gamma F_{A}+\frac{\varepsilon}{\theta} z-n-\rho\right) / \underbrace{\frac{d a}{d t}}_{+}-\frac{z_{a}}{z_{n}} \\
& >\frac{\gamma F_{A A}+\frac{\varepsilon}{\theta} z_{a}}{\frac{z_{a}}{n}-\frac{\varepsilon}{\theta} z_{n}}=\frac{\partial n^{*}}{\partial \tau} / \frac{\partial a^{*}}{\partial \tau}=\frac{n_{2}^{*}-n_{1}^{*}}{a_{2}^{*}-a_{1}^{*}} \\
& \Leftrightarrow \frac{\varepsilon}{\theta}-\frac{n+\rho-\gamma F_{A}}{z}>\left[\frac{z_{a}}{z_{n}}+\frac{\gamma F_{A A}+\frac{\varepsilon}{\theta} z_{a}}{z_{a} / n-\frac{\varepsilon}{\theta} z_{n}}\right] \frac{z_{n}}{z^{2}} \frac{d a}{d t}=-\frac{\gamma F_{A A}+\frac{z_{a}^{2}}{n z_{n}}}{(\underbrace{\frac{\varepsilon}{\theta}-\frac{z_{a}}{n z_{n}}}_{+}) z^{2}} \underbrace{\frac{d a}{d t}}_{+} \\
& \Leftrightarrow \quad\left(\frac{\varepsilon}{\theta}-\frac{z_{a}}{n z_{n}}\right)\left(\frac{\varepsilon}{\theta}-\frac{n+\rho-\gamma F_{A}}{z}\right)>-\left(\gamma F_{A A}+\frac{z_{a}^{2}}{n z_{n}}\right) \underbrace{\frac{1}{z^{2}} \frac{d a}{d t}}_{+} \\
& \Leftrightarrow \quad\left(\frac{\varepsilon}{\theta}\right)^{2}-\left(\frac{n+\rho-\gamma F_{A}}{z}+\frac{z_{a}}{n z_{n}}\right) \frac{\varepsilon}{\theta} \\
& \quad+\underbrace{\frac{n+\rho-\gamma F_{A}}{z} \frac{z_{a}}{n z_{n}}}_{+}+\left(\gamma F_{A A}+\frac{z_{a}^{2}}{n z_{n}}\right) \underbrace{\frac{1}{z^{2}} \frac{d a}{d t}}_{+}>0 .
\end{aligned}
$$

The saddle path $S_{2} S_{2}$ to the equilibrium with partial compensations, $\left(a_{2}^{*}, n_{2}^{*}\right)$, is below that $S_{1} S_{1}$ to the equilibrium with full compensations, $\left(a_{1}^{*}, n_{1}^{*}\right)$, as in Fig. 3, if and only if $S_{2} S_{2}$ falls less steeply than $\left(n_{2}^{*}-n_{1}^{*}\right) /\left(a_{2}^{*}-a_{1}^{*}\right)$. Given (37), this condition holds true with (31). 


\section{References:}

Becker GS (1991) A treatise on the family. Enlarged edition. Harvard University Press, Cambridge

Chesnais J-C (1992) The demographic transition: stages, patterns and economic implications. Oxford University Press, Oxford

Corneo G, Jeanne O (2001) On relative-wealth effects and long-run growth. Research in Economics 55(4):349-358

Festy P (1979) La féconfité des pays occidentaux de 1870 à 1970. Presses Universitaires de France, Paris

Fisher WH, Hof FX (2005) Status seeking in a small open economy. Journal of Macroeconomics 27(2):209-232

Galor O, Weil DN (2000) Population, technology, and growth: From Malthusian stagnation to the demographic transition and beyond. American Economic Review 90(4):806-826

Galor O, Moav O, Vollrath D (2009) Inequality in land ownership, the emergence of human capital promoting institutions and the great divergence. Review of Economic Studies 76(1):143-179

Guinnane TW (2011) The historical fertility transition: A guide for economists. Journal of Economic Literature 49(3):589-614

Gummins NJ (2013) Marital fertility and wealth during the fertility transition: Rural France, 1750-1850. Economic History Review 66(2):449-476

Kurz M (1968) Optimal economic growth and wealth effects. International Economic Review 9(3):348-357

Lehmijoki U, Palokangas T (2009) Population growth overshooting and trade in developing countries. Journal of Population Economics 22:43-56

Lehmijoki U, Palokangas T (2010) Trade, population growth, and the environment in developing countries. Journal of Population Economics 23(4):13511373

Lehmijoki U, Palokangas T (2013) Landowning, status and population growth. Economics Discussion Paper No. 651. University of Helsinki. Forthcoming as an article in the Springer Verlag book series "Dynamic Modeling and Econometrics in Economics and Finance".

Lucas REJ (2002)Lectures on economic growth. Harward University Press, Cambridge, Massachusetts

Maddison A (1995) Monitoring the world economy, 1820-1992. OECD, Paris 
Malthus TR (1798) An essay on the principle of population, as it affects the future improvement of society with remarks on the speculations of Mr. Godwin, M. Condorcet, and other writers. Printed For J. Johnson, In St. Paul's Church-Yard, London

Newbery DMG (1977) Sharecropping and uncertain labor markets. The Review of Economic Studies 44(3): 585-594

Razin A, Ben-Zion U (1975) An intergenerational model of population growth. American Economic Review 65:923-933

Smith A (1776) An inquiry into the nature and causes of the wealth of nations (1 ed). W Strahan, London

Stiglitz J (1974) Incentives and risk sharing in sharecropping. Review of Economic Studies 41:219û255

Weir DR (1994) New estimates of nuptiality and marital fertility in France, 1740-1911. Population Studies 48(2):307-331 